Tersedia Online di http://journal2.um.ac.id/index.php/jmsp/

ISSN Online : 2541-4429

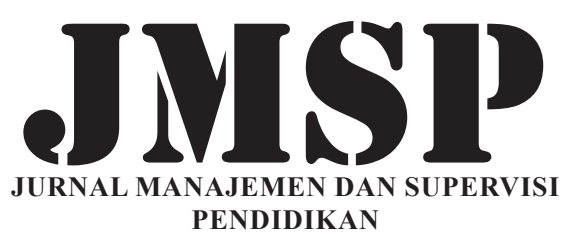

PENDIDIKAN

\title{
EVALUASI MANAJEMEN PEMASARAN JASA PENDIDIKAN NONFORMAL PUSAT KEGIATAN BELAJAR MASYARAKAT
}

\author{
Budi Handayani, Bambang Ismanto \\ Universitas Kristen Satya Wacana, Jalan Diponegoro 52-60 Sidorejo \\ Salatiga Jawa Tengah Indonesia \\ yanidinar6@gmail.com
}

\begin{abstract}
This study aims to evaluate the achievement of the marketing objectives of non-formal education services at the Salatiga City Community Learning Activity Center. This study uses a goal-oriented evaluation model developed by Ralph Winfred Tyler. Data collected using interviews, observation, and documentation. As a source of data is the manager, program manager, and student guardians. Data analysis uses qualitative analysis. The evaluation results show that the marketing management of educational services has been carried out by all PKBM managers with a marketing mix of 7P (product, price, place, promotion, people, process, physical evidence) but has not yet maximized in building a partnership called $1 \mathrm{P}$, namely partnership building.
\end{abstract}

Keywords: evaluation, marketing management of educational services, community learning center activities

\begin{abstract}
Abstrak: Penelitian ini bertujuan untuk mengevaluasi ketercapaian tujuan pemasaran jasa pendidikan nonformal Pusat Kegiatan Belajar Masyarakat Kota Salatiga. Penelitian ini menggunakan model evaluasi berorientasi pada tujuan (goal oriented evaluation model) yang dikembangkan oleh Ralph Winfred Tyler. Data dikumpulkan dengan menggunakan wawancara, observasi, dan dokumentasi. Sebagai sumber data adalah pengelola, penanggung jawab program, dan wali murid. Analisis data menggunakan analisis kualitatif. Hasil evaluasi menunjukkan bahwa manajemen pemasaran jasa pendidikan sudah dilakukan oleh semua pengelola PKBM dengan analisis marketing mix 7P (product, price, place, promotion, people, process, physical evidence) namun belum memaksimalkan dalam membangun kemitraan yang disebut 1P yaitu partnership building.
\end{abstract}

Kata Kunci: evaluasi, manajemen pemasaran jasa pendidikan, pusat kegiatan belajar masyarakat

Sekolah memberikan pelayanan kepada konsumen jasa pendidikan dengan tujuan untuk menambah kepercayaan masyarakat dan juga sebagai bahan promosi sekolah. Jasa pendidikan berperanan penting untuk mengembangkan dan meningkatkan kualitas sumber daya manusia, untuk penerapan pemasarannya harus menerapkan prinsip-prinsip terpadu. Prinsip-prinsip terpadu tersebut antara lain kegiatan hubungan masyarakat, komunikasi pemasaran, periklanan dan kegiatan lain yang dapat membantu pemasaran jasa pendidikan (Setiowati, 2016; Alma, 2009; David, 2013). Pendidikan sebagai produk jasa merupakan sesuatu yang tidak berwujud akan tetapi dapat memenuhi kebutuhan konsumen yang diproses dengan menggunakan atau tidak menggunakan bantuan produk fisik dimana proses yang terjadi merupakan interaksi antara penyedia jasa dengan pengguna jasa yang mempunyai sifat yang tidak mengakibatkan peralihan hak atau kepemilikan.

Evaluasi program adalah proses untuk mengetahui apakah tujuan pendidikan sudah dapat terealisasikan. Isaac membedakan empat ragam model evaluasi yang dapat digunakan untuk membedakan ragam model evaluasi, yaitu: (1) berorientasi pada tujuan program goal oriented; (2) berorientasi pada keputusan decision oriented; (3) berorientasi pada kegiatan dan orang-orang yang menanganinya transaction oriented; dan (4) berorientasi pada pengaruh dan dampak program research oriented (Arikunto, 2011; Anjani, dkk., 2018). Goal Oriented Evaluation Model yang dikembangkan oleh Tyler (Arikunto, 2011). Obyek pengamatan model ini adalah tujuan dari program yang sudah 
ditetapkan jauh sebelum program dimulai. Evaluasi dilakukan secara berkesinambungan, terus menerus, mengecek sejauh mana tujuan terlaksana di dalam proses pelaksanaan program.

PKBM adalah suatu wadah berbagai kegiatan pembelajaran di masyarakat yang diarahkan untuk pemberdayaan potensi dalam menggerakkan pembangunan di bidang sosial, ekonomi, dan budaya (Kemdikbud, 2017; Engchun, dkk., 2018). Pembentukan PKBM bertujuan untuk memperluas kesempatan masyarakat, khususnya masyarakat yang tidak mampu untuk melanjutkan usahanya dalam meningkatkan pengetahuan, ketrampilan dan sikap mental untuk pengembangan diri secara mandiri ekonomi. PKBM memiliki tugas pokok untuk memberikan kemudahan bagi masyarakat khususnya masyarakat kurang mampu untuk mengembangkan diri melalui penyelenggaraan pendidikan luar sekolah. Sesuai dengan Undang-undang Nomor 20 Tahun 2003 tentang Sistem Pendidikan Nasional pasal 1 ayat 12 menyatakan bahwa pendidikan nonformal merupakan jalur pendidikan diluar pendidikan formal yang pelaksanaanya secara terstruktur dan berjenjang. Pendidikan nonformal dapat berfungsi sebagai pelengkap, penambah dan sebagai lembaga lain yang berdiri sendiri substitutive.

PKBM memiliki beberapa program diantaranya: (1) program kesetaraan (Paket A setara SD, Paket B setara SMP, dan Paket C setara SMA/SMK); (2) Program Taman Baca Masyarakat (TBM); (3) Program Pendidikan Kesetaraan Inklusi; (4) Program Pendidikan Anak Usia Dini (PAUD); (5) Program Life Skill (Ketrampilan); (6) Program Keaksaraan (bagi buta aksara); (7) Homescholling; (8) bimbel; (9) peternakan; (10) pertanian; (11) perkebunan; dan (12) Kelompok Usaha Mandiri (KUM). Semua program tersebut disahkan diakta notaris, Kemkumham, dan ijin operasional dari Disdik Kabupaten/ Kota.

Kota Salatiga memiliki sepuluh PKBM yang masih aktif melayani masyarakat, diantaranya: (1) PKBM Permata; (2) PKBM Sunan Giri; (3) PKBM Al Islah; (4) PKBM Karisma; (5) PKBM Tunas Harapan; (6) PKBM Al Qufron; (7) PKBM Destiny; (8) PKBM Qoryah Thayyibah; (9) PKBM Marga Yasa; dan (10) PKBM Piwulang Becik. Kesepuluh PKBM tersebut memiliki Keunggulan dan keunikan masing-masing dalam memasarkan program-program yang dimiliki oleh satuan pendidikannya. Permasalahan yang paling nampak adalah penyerapan warga belajar/peserta didik yang sangat bervariatif diantara kesepuluh PKBM tersebut. Suksesnya sebuah tujuan apabila dilakukan dengan strategi jitu terandalkan.

Penelitian ini fokus pada evaluasi manajemen jasa pendidikan nonformal di pusat kegiatan belajar masyarakat KOTA Salatiga dengan menggunakan strategi marketing mix (bauran pemasaran) jasa 7P + 1P, yaitu: product (program) yang diberikan, place (tempat distribusi), price (harganya), promotion (bagaimana promosinya), people (SDM), process (proses), physical evidence (lingkungan fisik), dan partnership building (membangun kemitraan).

\section{METODE}

Penelitian evaluasi manajemen pemasaran jasa pendidikan nonformal di Pusat Kegiatan Belajar Masyarakat Kota Salatiga ini menggunakan model Goal Oriented Evaluation Model yang dikembangkan oleh Tyler (Arikunto, 2011). Penelitian dilakukan di seluruh Pusat Kegiatan Belajar Masyarakat seKota Salatiga yang berjumlah sepuluh Pusat Kegiatan Belajar Masyarakat. Subyek penelitian adalah pengelola / ketua Pusat Kegiatan Belajar Masyarakat, Pendidikan Nonformal Pendidikan Dasar Kota Salatiga, dan orang tua/wali siswa. Teknik pengumpulan data melalui wawancara, dokumentasi, dan observasi. Analisis hasilnya berdasarkan tanggapan dan dokumen-dokumen yang diperoleh dari nara sumber yang kemudian dianalisis secara kualitatif.

Langkah yang dilakukan sesuai goal oriented evaluation model, terdiri dari: menetapkan tujuan umum, menggolongkan sasaran atau tujuan, mendefinisikan tujuan dalam konteks istilah perilaku, menentukan situasi dimana pencapaian tujuan dapat ditunjukkan, mengembangkan atau memilih tehnik pengukuran, mengumpulkan data kinerja dan membandingkan data kinerja dengan perilaku yang menggambarkan tujuan. 


\section{HASIL DAN PEMBAHASAN}

Evaluasi umum pemasaran jasa pendidikan PKBM. Tujuan utama dari pemberdayaan sebagai upaya untuk membelajarkan masyarakat dalam mengentaskan kemiskinan yang berprinsip pada pengembangan dalam perwujudan demokrasi bidang pendidikan. Kegiatan tersebut untuk: (1) memberdayakan masyarakat agar mampu mandiri (berdaya); (2) meningkatkan kualitas hidup masyarakat dari segi social ekonomi; dan (3) meningkatkan kepekaan terhadap masalah-masalah yang terjadi dilingkungan untuk mampu memecahkan segala persoalan.

Evaluasi sasaran atau tujuan pemasaran PKBM. Pemasaran yang dilakukan oleh manajerial (pengelola) dan penanggung jawab program terlebih dahulu mengenal dan memahami: what, who, where, when, why, dan how peluang yang ada pada calon konsumen / pelanggan yaitu masyarakat. Masyarakat ynag bermasalah dari berbagai latar belakang sosial, ekonomi, budaya, dan lain sebagainya untuk kembali bersekolah dan mengenyam pendidikan di jalur pendidikan nonformal PKBM. Evaluasi Perilaku konsumen PKBM. Adanya kenaikan jumlah peserta didik dari tahun ke tahun sesuai data di Manajemen Dapodik PAUD dan DIKMAS per Tahun 2019 (Tabel 1).

Tabel 1 Jumlah Peserta Didik

\begin{tabular}{|c|c|}
\hline Tahun & Jumlah Peserta Didik \\
\hline 2016 & 314.994 orang \\
\hline 2017 & 479.392 orang \\
\hline 2018 & 1.149 .866 orang \\
\hline 2019 & 1.278 .949 orang \\
\hline
\end{tabular}

Pada analisis ini tentang profil umum Pusat Kegiatan Belajar Masyarakat di Salatiga yang tersebar di empat Kecamatan yaitu: (1) Kecamatan Sidorejo (Permata \& Karisma); (2) Kecamatan Sidomukti (AlGufron, Destiny Institute); (3) Kecamatan Argomulyo (Sunan Giri, Tunas Harapan); dan (4) Kecamatan Tingkir (Al Islah, Qoryah Thayyibah, Marga Yasa dan Piwulang Becik). Kesepuluh Pusat Kegiatan Belajar Masyarakat di Kota Salatiga, masing-masing Pusat Kegiatan Belajar Masyarakat memiliki karakteristik dan keunikan dalam melakukan metode pembelajaran yang menjadi suatu daya tarik untuk peserta didik (warga belajar) untuk mendaftar dan mengikuti pembelajarannya.

Metode pembelajaran Pusat Kegiatan Belajar Masyarakat Kota Salatiga dapat dibagi ke dalam beberapa metode: (1) Pusat Kegiatan Belajar Masyarakat yang menerapkan metode pembelajaran klasikal, tatap muka dan mandiri (konvensional) seperti yang dilakukan di sekolah-sekolah formal terdiri dari Pusat Kegiatan Belajar Masyarakat Permata, Pusat Kegiatan Belajar Masyarakat Karisma, Pusat Kegiatan Belajar Masyarakat Al Islah, dan Pusat Kegiatan Belajar Masyarakat Al Qufron; (2) Pusat Kegiatan Belajar Masyarakat yang menerapkan metode pembelajaran Daring (dalam jaringan) dengan aplikasi Moodle 2017 dan setara daring Kemdikbud yaitu Pusat Kegiatan Belajar Masyarakat Tunas Harapan, dan yang sedang dalam rintisan daring Pusat Kegiatan Belajar Masyarakat Sunan Giri dan Piwulang Becik; (3) Pusat Kegiatan Belajar Masyarakat yang menerapkan metode pembelajaran melalui komunitas belajar yang berfokus pada bakat, minat warga belajar adalah Pusat Kegiatan Belajar Masyarakat Qoryah Thayyibah; dan (4) Pusat Kegiatan Belajar Masyarakat yang menerapkan sistem blended learning, metode mencampurkan antara pembelajaran konvensional dan life skill terdiri dari Pusat Kegiatan Belajar Masyarakat Destiny, Pusat Kegiatan Belajar Masyarakat Marga Yasa.

Hasil evaluasi profil Pusat Kegiatan Belajar Masyarakat secara umum diketahui bahwa metode pembelajaran yang dilakukan masing-masing memiliki metode beragam, diantaranya; metode klasikal, tatap muka, mandiri, rintisan daring, daring, luring dan blended antara klasikal, tatap muka, mandiri dan life skill. Pada dasarnya strategi marketing mix sudah dianalisis dan dilakukan oleh masingmasing Pusat Kegiatan Belajar Masyarakat di Kota Salatiga. Meskipun pelaksanaanya dengan cara yang berbeda-beda namun tetap memiliki tujuan yang sama yaitu produk atau program-program yang 
ditawarkan di PKBM dapat terjual di masyarakat pengguna. Kebermanfaatan program-program layanan dapat memberi kebermanfaatan bagi masyarakat. Keberhasilan penyerapan layanan dapat diketahui dari indikasi jumlah peserta didik / warga yang ikut belajar di Pusat Kegiatan Belajar Masyarakat.

Pelaksanaan strategi manajemen strategi 7P pemasaran jasa Pendidikan Nonformal yang dilakukan oleh masing-masing pengelola learning centers yaitu: (1) memiliki product berupa Program Paket C, baru merintis program Paket A dan B, memiliki program pendukung Taman Baca Masyarakat; (2) karisma, memiliki product berupa Program Kesetaraan Paket A, B, dan C, Pendidikan Anak Usia Dini, Taman Baca Masyarakat; (3) Al Qufron melakukan strategi pemasarannya dengan memiliki product berupa Program Kesetaraan Paket B dan C, belum memiliki Paket A, Pendidikan Anak Usia Dini, Taman Baca Masyarakat Harmoni; (4) Sunan Giri, product berupa Program Kesetaraan Paket A, B, dan C, Taman Baca Masyarakat; (5) Al Islah, memiliki product berupa Program Kesetaraan Paket B dan C, Rintisan Taman Baca Masyarakat; (6) Marga Yasa, product yang dimiliki berupa Program Kesetaraan Paket B dan C, Taman Baca Masyarakat Kejora, Bimbel, Bimbingan Konseling, Kesetaraan Paket A, B, dan C Inklusi, Trainning Center Sumber Daya Manusia; (7) Tunas Harapan, memiliki product berupa Program Kesetaraan Paket A, B, dan C; (8) Qoryah Thayyibah, memiliki product berupa Program Kesetaraan Paket B dan C, Pendidikan Anak Usia Dini, Taman Baca Masyarakat; (9) Destiny Institute, product program yang dimiliki Program Kesetaraan Paket A, B, dan C, Taman Baca Masyarakat, dan life skill (musik); dan (10) Piwulang Becik, memiliki product Program Kesetaraan Paket A, B, dan C, Taman Baca Masyarakat dan life skill (kesenian dan musik).

Pada dasarnya pengelola sudah melakukan analisis dan strategi bauran pemasaran. Diketahui dari beragam jumlah peserta didik yang diserap dari masing-masing PKBM. Dari yang berjumlah puluhan hingga ratusan peserta didik. Dari telaah 7P ternyata banyak keragaman yang dilakukan, dari penyelenggaraan program layanan (product) berupa Pendidikan Kesetaraan Paket A/B/C, Pendidikan Kesetaraan Paket A/B/C inklusi, Pendidikan Anak Usia Dini, Homeschooling, Taman Baca Masyarakat, pertanian, perikanan, bimbingan belajar, bimbingan konseling, training Sumber Daya Manusia, dan lain-lain. Penentuan price biaya bulanan (Sumbangan Pembinaan Pendidikan / SPP) sangat bervariatif jumlahnya dari Rp. 30.000,00 sampai sekitar Rp. 1.000.000,00 bahkan ada yang memakai sistem sukarela dan menggratiskan SPP, kegiatan promosi (promotion) dilakukan dengan berbagai macam cara, yaitu dengan word to mouth, pendekatan persuasive ke kehidupan sosial kemasyarakatan, penjaringan dari data Anak Tidak Sekolah, publikasi medsos website, IG, Facebook, sosialisasi ke kelurahan, menggunakan brosur/leaflet, dengan mendeskripsikan perubahan positif karakter anak ke orang tua walisiswa, expo, dan pameran pendidikan, mengikuti lomba-lomba untuk peserta didik, dan mempublikasikan kegiatan Pusat Kegiatan Belajar Masyarakat melalui media cetak (koran).

Place, tempat untuk beraktivitas di gedung sendiri, pinjam pakai di sekolah formal yang sudah di regrouping, pinjam pakai di sekolah formal yang masih aktif Kegiatan Belajar Mengajarnya serta pinjam pakai di rumah penduduk. Sumber Daya Manusia (People) sudah merekrut Tenaga Pendidik dan Tenaga Kependidikan yang sesuai dengan kualifikasi dan kompetensi dengan kelinieran mata pelajaran. Proses (Process) kegiatan belajar yang dilakukan dengan menggunakan Kurikulum Tingkat Satuan Pelajaran (KTSP), Kelas baru sudah menggunakan Kurikulum 2013 Pendidikan Kesetaraan, da nada juga Kurikulum Cambridge yang berbasis dalam jaringan (daring), rintisan dalam jaringan (daring), dan berbasis di luar jaringan (luring), sedang untuk proses manajemen pembiayaan cenderung belum memiliki kegiatan menciptakan unit usaha produktif. Kondisi lingkungan dan peralatan penunjang kegiatan belajar mengajar (sarana prasarana) secara keseluruhan sudah dapat menunjang proses pembelajaran yang kondusif. Partnership building rata-rata belum maksimal membangun kerjasama kemitraan untuk memperkuat jaringan usaha/kerja.

Kebutuhan pengembangan strategi marketing jasa pendidikan perlu dilakukan secara berkesinambungan dan menyeluruh agar dapat menumbuhkan daya saing terhadap sekolah yang lainnya. Peranan sekolah, baik sekolah formal maupun nonformal perlu dilakukan dalam tiga hal yaitu: (1) membuat anak didik belajar bergaul dengan semua warga sekolah; (2) membuat anak didik menaati peraturan-peraturan sekolah; dan (3) mempersiapkan anak didik untuk menjadi anggota masyarakat yang berguna bagi agama, bangsa, dan negara (Faisal, 2015; Kamil, 2011). Pusat Kegiatan Belajar 
Masyarakat (PKBM) sebagai salah satu lembaga penyelenggara satuan pendidikan luar sekolah (PLS) yang bervisi untuk pemberdayaan masyarakat untuk meningkatkan kualitas hidupnya.

Penyelenggara pendidikan nonformal dituntut agar lebih kreatif dan inovatif dalam menggali keunikan dan keunggulan lembaganya agar semakin diminati masyarakat sebagai pengguna jasa pendidikan. Untuk mempertahankan eksistensi, keberlangsungan dan kesinambungan program-program PKBM maka perlu adanya evaluasi manajemen pemasaran jasa pendidikan non formal di PKBM kota Salatiga Peran PKBM di masyarakat dalam memecahkan persoalan-persoalan yang terjadi. PKBM dibutuhkan masyarakat. Evaluasi manajemen pemasaran jasa pendidikan nonformal di PKBM Kota Salatiga penting dilakukan (Hasthanti, 2018; Nugroho, 2013; Ridwan, 2017), mengingat kebutuhan dan animo masyarakat semakin meningkat yang dapat dilihat dari peningkatan jumlah peserta didik di PKBM dalam kurun waktu 2016 s.d. 2019 mengalami kenaikan grafik yang signifikan.

Beberapa penelitian tentang marketing mix atau bauran pemasaran jasa pendidikan telah dilakukan sebelumnya, yaitu Harahab (2018) menyimpulkan lembaga sudah menerapkan bauran pemasaran (marketing mix) 7P dalam proses pemasaran pendidikannya. Dalam perkembangan pemasaran memunculkan sesuatu yang baru, khususnya dalam hal pelayanan dan fasilitas (Ružinská, 2018; Sunyoto \& Susanti, 2015). Berbeda dengan Anwar (2014) hasil penelitiannya menunjukkan bahwa strategi pemasaran jasa pendidikan yang dilakukan untuk meningkatkan peminat layanan jasa pendidikan menggunakan pemasaran secara langsung dan marketing tidak langsung lewat optimalisasi kegiatan madrasah. Sementara itu Fathonah (2106) menyimpulkan peningkatan jumlah siswa menggunakan strategi pemasaran jasa pendidikan. Penelitian Setiowati (2016) menyimpulkan pemasaran yang didasarkan pada semakin bertambahnya siswa SD Kristen YSKI yang tidak melanjutkan ke SMP Kristen YSKI selama lima tahun terakhir.

\section{SIMPULAN}

Hasil evaluasi diatas menunjukkan bahwa pelaksanaan manajemen pemasaran jasa pendidikan Nonformal di Pusat Kegiatan Belajar Masyarakat Kota Salatiga sudah dilakukan dengan menerapkan seluruh bauran pemasaran 7P. Rata-rata memiliki keunggulan di product (program layanannya), price (SPP yang bervariatif), promotion (promosi dengan berbagai metode), people (sumber daya manusia berupa pendidik dan tenaga kependidikan yang berkualitas). Lingkungan fisik physical evidence sudah cukup kondusif untuk kegiatan penyelenggaraan program. Untuk unsur process pembelajaran belum memaksimalkan jaringan internet wifi untuk pembelajaran dalam jaringan (daring) yang terintegrasi dengan pusat-pusat literasi. Place, tempat kegiatan pembelajaran masih ada yang belum memiliki gedung sendiri dan masih pinjam dirumah penduduk dan unsur membangun kerjasama kemitraan partnership building belum dilakukan secara maksimal dibuktikan dengan adanya satuan pendidikan pendidikan non formal Pusat Kegiatan Belajar Masyarakat yang belum memiliki Memo of Understanding (MoU) dengan mitra untuk membuat jejaring usaha.

\section{DAFTAR RUJUKAN}

Alma, B. (2009). Manajemen Pemasaran dan Pemasaran Jasa. Bandung: Alfabeta.

Anjani, H. D., Irham, \& Waluyati, L. R. (2018). Relationship of 7P Marketing Mix and Consumers'Loyalty in Traditional Markets. (Online), (https://jurnal.ugm.ac.id/jae/article/view/36400), diakses 3 Mei 2019.

Anwar, D. (2014). Strategi Pemasaran Jasa Pendidikan dalam Meningkatkan Peminat Layanan Pendidikan di Madrasah Mualimin Muhammadiyah Yogyakarta. (Online), (http://digilib.uin-suka. ac.id/15112/2/1220411215bab-iv-atau-v-daftar-pustaka.pdf), diakses 3 Mei 2019.

Arikunto, S. (2011). Evaluasi Program Pendidikan: Pedoman Teoritis Praktis Bagi Mahasiswa dan Praktisi Pendidikan. Jakarta: PT Bumi Aksara.

David, A. A. (2013). Manajemen Strategis. Jakarta Selatan: Salemba Empat.

Engchun, R., Sungtong, E., \& Haruthaithanasan, T. (2018). Homeschooling in Southern Thailand: Status and Proposed Guidelines for Learning Process Management. (Online), (https://www.sciencedirect.com/science/ article/pii/S2452315116301357), diakses 3 Mei 2019. 
Faisal, Y. (2015). Manajemen Pemasaran Jasa Pendidikan di Lembaga Kursus dan Pelatihan Bugs Training Center Sleman. Yogyakarta: Universitas Negeri Yogyakarta.

Fathonah, K. (2016). Strategi Pemasaran Jasa Pendidikan dalam Meningkatkan Pelayanan Pendidikan di MAN I Sragen. (Online), (http://eprints.iain-surakarta.ac.id/172/1/tesis\%20full.pdf), diakses 3 Mei 2019.

Harahab, N. (2018). Marketing Jasa Pendidikan di MI Muhammadiyah Program Khusus Kartasura. (Online), (http://eprints.ums.ac.id/69158/1/NASKAH\%20PUBLIKASI.pdf), diakses 3 Mei 2019.

Hasthanti, S. W. (2018). Analisis Marketing Jasa Pendidikan di SD Muhammdiyah Plus Salatiga. Surakarta: Magister Administrasi Pendidikan UMS.

Kamil, M. (2011). Pendidikan Nonformal. Bandung: Alfabeta.

Kemdikbud. (2017). Model Unggulan Pendidikan Masyarakat. Jakarta: Dirjen Paud dan Dikmas, Kemdikbud.

Nugroho, C. W. (2013). Strategi Pemasaran Program Studi dan Strategi Blue Ocean. Salatiga: Magister Manajemen Pendidikan UKSW.

Ridwan. (2017). Manajemen Pemasaran Pendidikan Nonformal Studi Kasus di Desa Bahasa Borobudur. (Online), (http://digilib.uin-suka.ac.id/26952/1/12490052_BAB-I_IV-atau-V-DAFTAR-PUSTAKA.pdf), diakses 3 Mei 2019.

Ružinská, E. 2018. The Analysis of Selected Aspects of Marketing in Educational Institution. (Online), (http:// www.mladaveda.sk/casopisy/2018/01/01_2018_05.pdf), diakses 3 Mei 2019.

Setiowati, D. (2016). Strategi Bauran Pemasaran Jasa Sekolah (Studi Kasus the Lost Customer SMP Kristen YSKI Semarang). (Online), (http://repository.unika.ac.id/11843/1/12.90.0002\%20Desy\%20Setiowati\%20COVER. pdf), diakses 3 Mei 2019.

Sunyoto, D., \& Susanti, F. E. (2015). Manajemen Pemasaran Jasa. Yogyakarta: CAPS.

Undang-undang Nomor 20 Tahun 2003 tentang Sistem Pendidikan Nasional. 2013. Jakarta: Fokus Media. 